\title{
Warm-up exercises based on variability
}

\section{Fernando Vilches}

Argentine Tennis Association.

\begin{abstract}
The proper structuring of the content to be developed in a tennis session is one of its most important aspects. Within this structure, the warm-up is a part that should always be present. Despite its importance, on many occasions, the warm-up does not receive from the coaches all the attention it should. The present article proposes a number of methodological tools based on variability training principles with the aim of providing greater specificity and quality to the tennis warm-up.
\end{abstract}

Key words: warm-up, variability, problem solving

Received: 25 January 2021

Acepted: 30 March 2021

Corresponding author: Fernando Vilches, Argentine Tennis Association. Maipú 471, C1006 CABA. Argentina. Email: fervilches@hotmail.com

\section{INTRODUCTION}

The correct structuring of the session is a key factor for its success. Several authors indicate that it should follow a logical structure in terms of intensity, starting with some prior exercises in preparation for the main part, in the which the objectives set will be carried out through the relevant content (Devís and Peiró, 1992; Delgado et al., 1999; Serra, 1996). Despite its valuable benefits, the warm-up is often underestimated by both coaches and players, minimizing its importance for the incorporation of different work content.

On the other hand, tennis is an open skill sport, as it is subject to changing stimuli from the environment. Therefore, the learning process of the student should be adapted so that a greater number of stimuli is introduced. This variety of stimuli would permit the player to adapt in a more efficient way to problematic situations that the game will introduce (Sanz et al., 2012). Therefore, tennis training should be varied, changeable and random to produce deeper learning and greater transfer of skills to the real game (Reid et al., 2007; Schmidt et al., 2008).

\section{VARIABILITY LINKED TO WARM-UP}

Variability is an intrinsic component of all biological systems, since it is a functional element that facilitates learning and internalising new coordinative structures. In addition, it provides flexibility to the neuromotor system facilitating the learning of new patterns (Araujo et al., 2006). With regard to tennis training specifically, the variable practice or variability in training refers to the process of creating situations that generate an imbalance in the execution. This forces players to spontaneously find new individual movement patterns adapted to the conditions. These new patterns will allow them to increase their motor efficiency (Sanz, Fernández, Zierof, \& Mendez, 2012).

One of the most important principles that all warm-up must comply with is that of specificity. This principle refers to the need for activities during warmup to consider the characteristics of sport in intensity, structures involved or coordination capacities (Unierzynski, Boguslawski, \& Wheatley, 2018). Therefore, variability training can be an ideal tool to increase the specificity of the warm-up and facilitate the desired adaptations to occur, not only at a physiological level but also at a neuronal and psychological level (Sanz \& Hernández, 2013).

Next, a proposal of warm-up exercises based on variability training with different specific objectives is presented. The objective of this proposal is merely to exemplify a series of examples that can serve as inspiration for coaches to create their own, based on their objectives and the characteristics of their players.

\section{PROPOSAL OF WARM-UP EXERCISES}

\section{Mobility}

Exercise 1: Both players rally in the service boxes, after hitting the ball they must touch the line marked in front of them with one of their feet and return to their starting position (Figure 1).

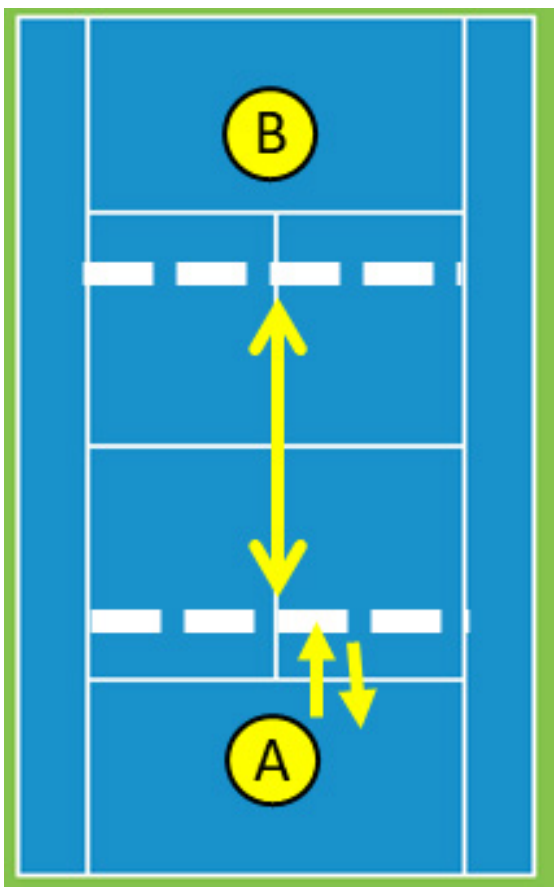

Figure 1. 
Exercise 2: Both players rally in the service boxes, after hitting the ball they must touch with one of the feet behind the cone and return to their starting position (Figure 2).

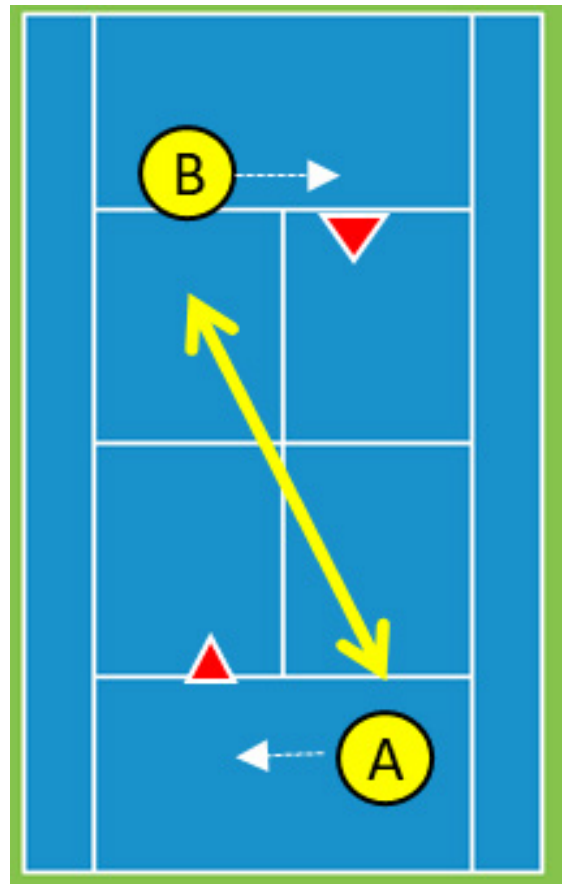

Figure 2.

Exercise 3: Both players rally in squares from $s$ to which, after hitting the ball, they must recover from behind the cone located at the "T" (Figure 3).

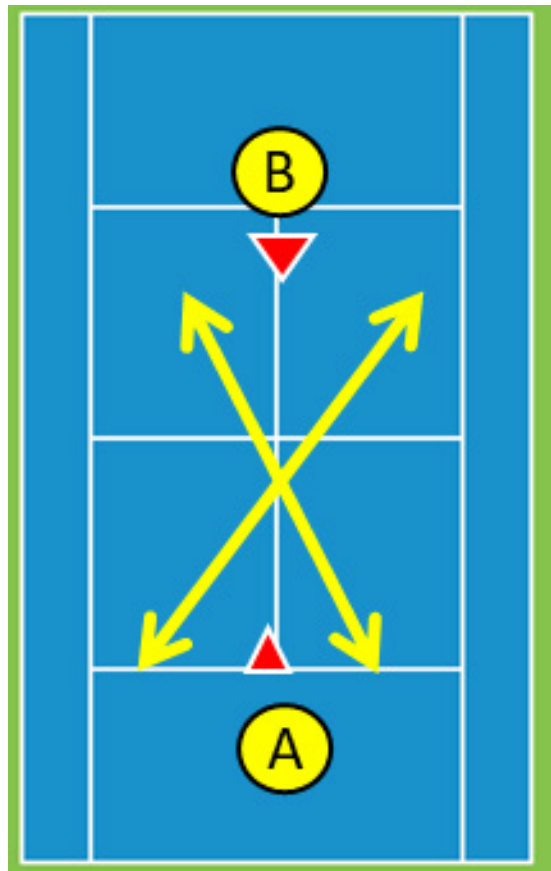

Figure 3.

\section{Control / precision:}

Exercise 4: Both players rally in the service boxes trying to keep the ball in play a certain number of times (for example 15). Once they have met this goal, they switch to another ball with a different pressure level (Figure 4).

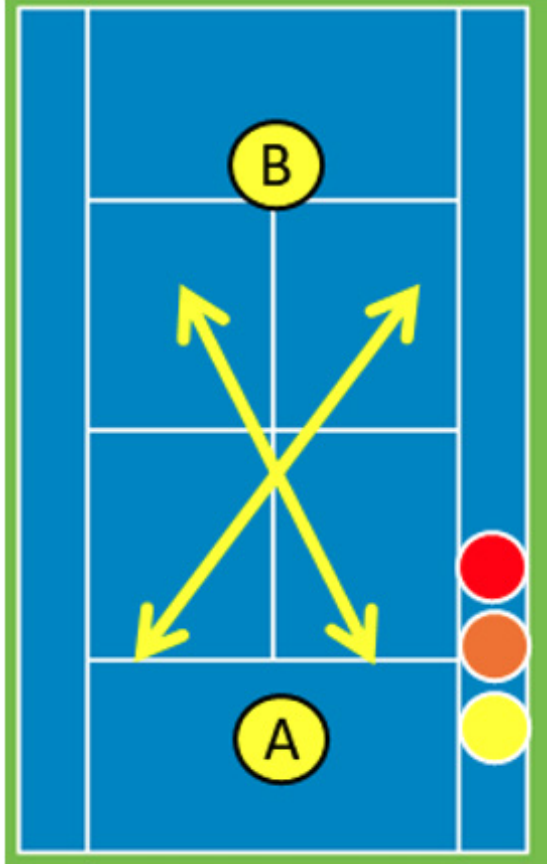

Figure 4.

Exercise 5: Both players rally in the service boxes trying to keep the ball in play a certain number of times within the defined spaces. As a progression, players can be asked to try to alternate three speeds $(1,2,3)$ in the intensity of hitting the ball (Figure 5).

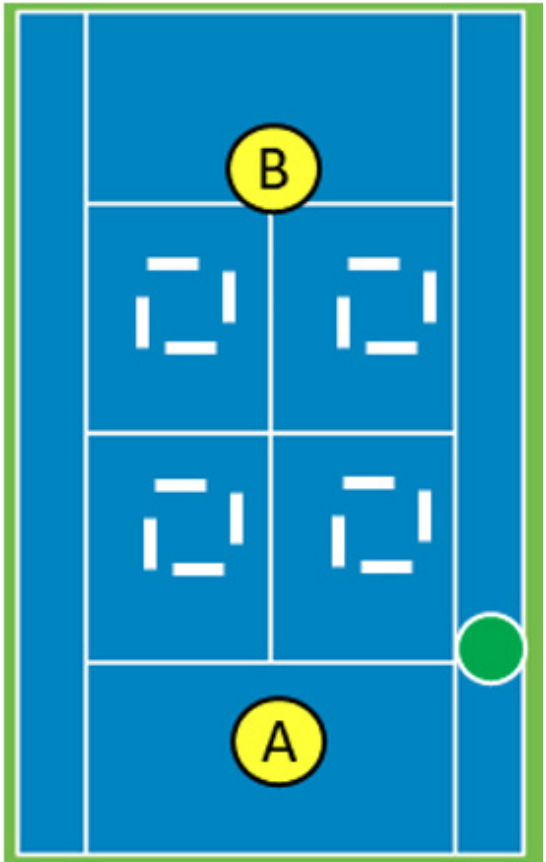

Figure 5. 


\section{Concentration:}

Exercise 6: Both players rally trying to knock down the cone of the opposite field located in certain areas, each time a player turns a cone he adds a certain score (Figure 6).

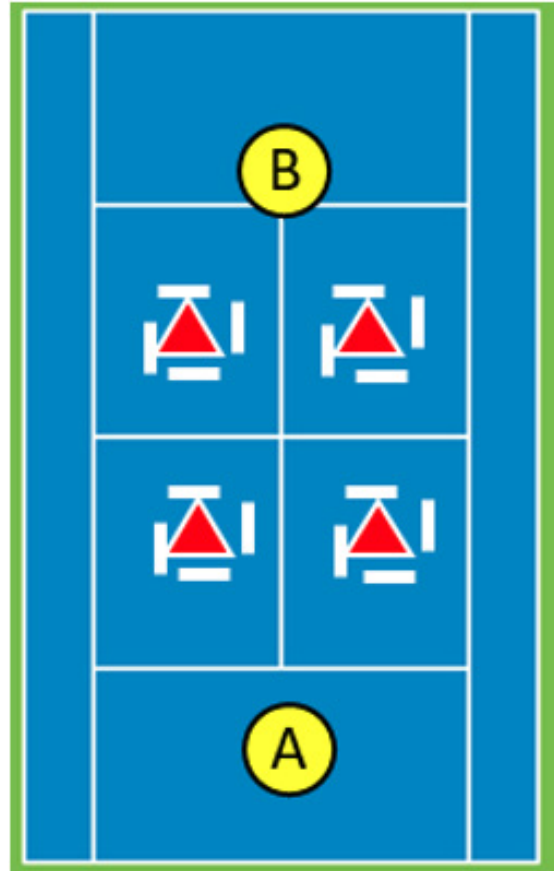

Figure 6.

Exercise 7: Both players rally in a certain direction, trying to play the ball between the cones defined in the opposite field (Figure 7).

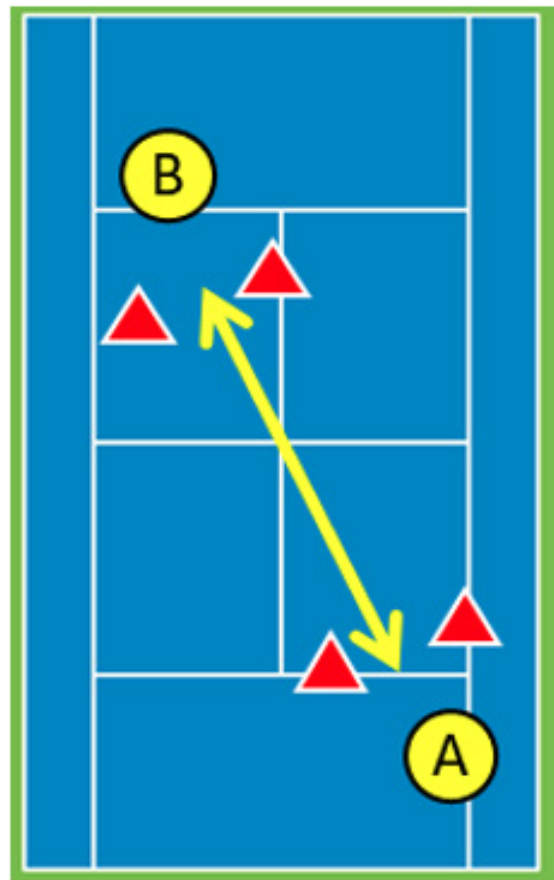

Figure 7.
Exercise 8: Both players rally in a certain direction, both start with an initial score of 10 , each time the ball bounces in the + zone they add 1 point, each time it bounces in the - zone they subtract one point. The objective is for the players to achieve the maximum number of points possible while rallying and adding together (Figure 8).

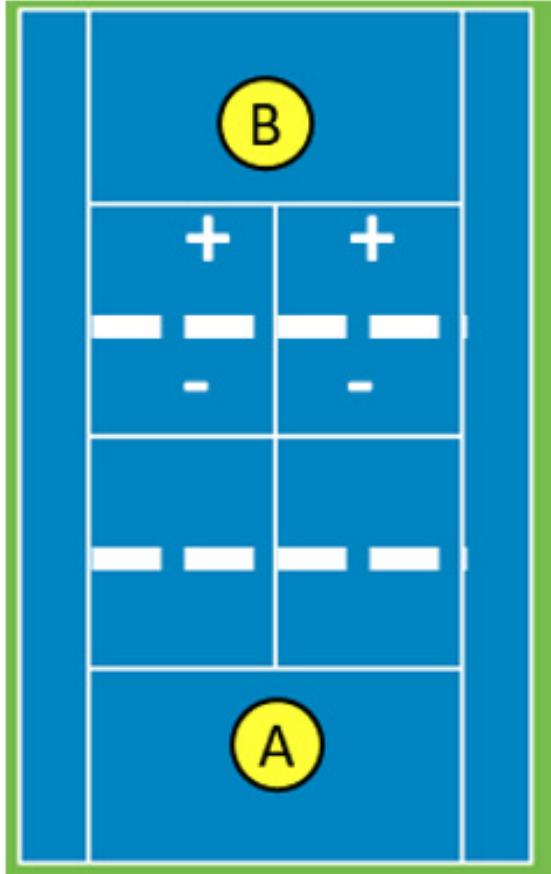

Figure 8.

Explanatory note: All exercises can be adapted to the skill level of the players. The area of the court where the drills are performed can also be modified, in this example the graphs show the drills in the service square, but they can also be done from three quarters or back of the court.

\section{CONCLUSIONS}

As it can be seen, the use of exercises based on variability within the warm-up can favour its specificity and facilitate the fulfilment of both physiological and psychological objectives. In addition, these exercises provide a great amount of problem situations that the player must solve, which will allow to acquire a wider repertoire of tools when responding to demands that are present in the different game situations.

\section{REFERENCES}

Araujo, D., Davids, K., \& Hristovski, R. (2006). The ecological dynamics of decision making in sport. Psychology of sport and exercise, 7(6), 653-676. https://doi.org/10.1016/j.psychsport.2006.07.002

Delgado et al. (1999). Entrenamiento físico deportivo y alimentación: de la infancia a la edad adulta. Barcelona. Paidotribo. $2^{\circ}$ Edición.

Devís y Peiró (1997). Nuevas perspectivas curriculares en Educación Física: la salud y los juegos modificados. Barcelona. Inde. $2^{\circ}$ edición.

Elliot, B., Reid, M.,y Crespo, M. (2009). El desarrollo de la técnica en la producción de los golpes en el tenis. London: International Tennis Federation.

Fernández, J., Méndez, A., y Sanz, D. Fundamentos del entrenamiento de la condición física para jugadores de tenis en formación. Madrid. RFET. 2012.

Reid, M., Crespo, M., Lay, B., \& Berry, J. (2007). Skill acquisition in tennis: Research and current practice. Journal of science and medicine in sport, 10(1), 1-10. https://doi.org/10.1016/j.jsams.2006.05.011

Sanz, D., Fernández, J., Zierof, P., \& Méndez, A. (2012). Variabilidad en la práctica para desarrollar las cualidades coordinativas de los tenistas en formación. ITF Coaching \& Sport Science Review, 58 (20), 16-18. 
Sanz, D. \& Hernández, J. (2013). Application of variable practice to technique training in tennis, ITF Coaching \& Sport Science Review, 60, 21-23.

Schmidt, R. A., y Wrisberg, C. A. (2008). Motor learning and performance: A situation-based learning approach. Human kinetics. Davids, K., Bennett, S. Newell, K.M., Movement System Variability. Champaign. Illinois. Human Kinetics., 2006.

Unierzynski, P., Boguslawski, M., \& Wheatley, S. (2018). Applied integrated training on-court - specific case studies: Is it a methodology of the future? ITF Coaching \& Sport Science Review, 75 (26), 31-33.

Copyright () 2021 Fernando Vilches

(c) (i)

This text is under a Creative Commons BY 4.0 license

You are free to Share - copy and redistribute the material in any medium or format - and Adapt the content - remix, transform, and build upon the material for any purpose, even commercially under the following terms:

Attribution: You must give appropriate credit, provide a link to the license, and indicate if changes were made. You may do so in any reasonable manner, but not in any way that suggests the licensor endorses you or your use. 